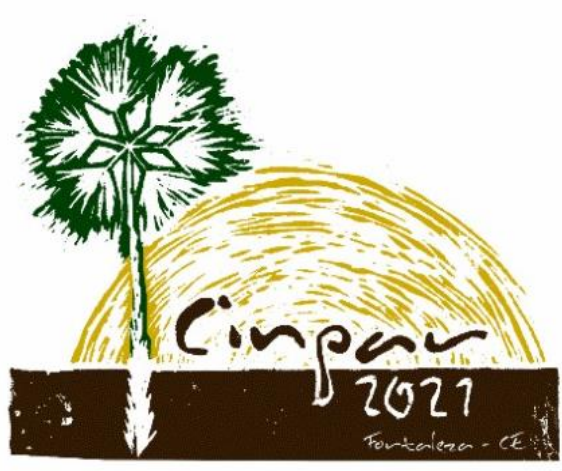

XVII Congresso Internacional sobre Patologia e

Reabilitação das Construções

XVII Congreso Internacional sobre Patología y Rehabilitación de las Construcciones

XVII International Conference on Pathology and Constructions Rehabilitation

FORTALEZA (Brasil), 3 a 5 de junho de 2021

https://doi.org/10.4322/CINPAR.2021.073

\title{
Manifestações patológicas: estudo de caso de uma edificação no município de Congonhas-MG
}

\section{Pathological manifestations: Case study of a building in the municipality of Congonhas -MG}

\author{
Débora SANTOS ${ }^{1}$, Felipe GUERRA ${ }^{2}$, Marina DONATO ${ }^{3}$ \\ ${ }^{1}$ Universidade Federal de São João Del Rei, Ouro Branco, Brasil, deboradavilasantos@gmail.com \\ 2 Universidade Federal de São João Del Rei, Ouro Branco, Brasil, felipe.piacesi@hotmail.com \\ ${ }^{3}$ Universidade Federal de São João Del Rei, Ouro Branco, Brasil, donato@ufsj.edu.br
}

\begin{abstract}
Resumo: As manifestações patológicas trazem transtornos para os usuários, assim como para o construtor, pois os custos de uma intervenção após uma obra pronta são maiores se comparados aos custos de uma execução bem-feita. Este trabalho apresenta um estudo de caso de sobre manifestações patológicas caracterizadas por fissuras, trincas e umidade, ocorrendo com intensidades relevantes nas alvenarias da edificação. $O$ objetivo desta pesquisa é analisar e avaliar as manifestações patológicas de uma edificação a partir dos procedimentos normativos de inspeção visual. As fissuras e trincas presentes neste trabalho foram observadas em um intervalo de oito meses e durante este período foi construído um segundo pavimento aumentando a carga imposta à estrutura e, consequentemente, a tensão no solo. A avaliação das patologias na estrutura, neste caso, visa também observar o comportamento da estrutura para este acréscimo de cargas, se haveria aumento da abertura das fissuras e trincas ou mesmo se surgiriam outras patologias. Por fim, a conclusão do trabalho se fundamenta que as patologias presentes na edificação foram classificadas com grau de risco baixo e não comprometem a estrutura.
\end{abstract}

Palavras-chave: patologias, fissuras, trincas, umidade, estudo de caso.

\begin{abstract}
Pathological manifestations bring inconvenience to users, as well as to the builder, because the costs of an intervention after a finished work is higher when compared to the costs of a well-executed execution. The objective of this research is to analyze and evaluate the pathological manifestations of a building based on normative visual inspection procedures. This work presents a case study of pathological manifestations characterized by fissures, cracks and humidity, occurring with relevant intensities in the building's masonry. The objective of this research is to analyze and evaluate the pathological manifestations of a building based on normative visual inspection procedures. The cracks and cracks present in this work were observed in an interval of eight months and during this period a second floor was built, increasing the load imposed on the structure and, consequently, the tension in the soil. The evaluation of pathologies in the structure, in this case, also aims to observe the behavior of the structure for this increase in loads, whether there would be an increase in the opening of cracks and cracks or even if other pathologies would appear. Finally, the conclusion of the work is based on the fact that the pathologies present in the building were classified as low risk and do not compromise the structure.
\end{abstract}

Keywords: pathologies, fissures, cracks, humidity, case study. 


\section{Introdução}

Em uma obra deve-se ressaltar alguns elementos importantes da construção civil como a segurança, a estética, a higiene, a funcionalidade, contudo, não sendo menos importante e muitas vezes abandonados em algumas obras, os custos com manutenção e durabilidade, sendo que todos estes fatores estão ligados diretamente com as propriedades tecnológicas dos materiais de construção.

O processo construtivo deve ser executado de maneira que a edificação não apresente problemas que dificultem, ou inutilizem sua ocupação. Erros construtivos, muitas vezes causados pela má prática ou por uma tentativa de economia na execução de determinado empreendimento podem causar esforços em elementos que não são dimensionados para recebê-los. Gerando prejuízos, que podem ser estéticos, ou em casos mais graves estruturais.

As patologias mais comuns presentes em muitas construções são as trincas, fissuras, rachaduras e umidade que serão discutidas neste trabalho quanto a sua gravidade e risco para a edificação.

Ocupar uma edificação com fissuras e trincas pode ter um aspecto negativo para os usuários, objetivando o esclarecimento destes sintomas ocasionados em uma estrutura foi realizado um estudo de caso com o principal objetivo de identificar se a estrutura que foi ampliada sofreria com agravamento destes e se representaria um possível risco à segurança de seus ocupantes.

\section{Referências Bibliográficas}

Segundo Possan (2013), um dos problemas frequentes nas edificações é a degradação prematura e a perda de resistência. Causada pelo envelhecimento precoce das mesmas, esta deterioração é desencadeada pela baixa qualidade dos materiais de construção empregados, por problemas de projeto e execução e falta de manutenção.

De acordo com Souza e Ripper (1998), a construção pode ter um desempenho insatisfatório em algum momento da sua vida útil ou até mesmo antes da sua finalização, entretanto não significa que está condenada. Uma avaliação do problema deve ser feita sendo necessária uma intervenção técnica a fim de reabilitar a estrutura.

\subsection{Manifestações patológicas}

A classificação de patologias de acordo com Figueiredo (2003) é feita separando o problema e subdividindo de acordo com a provável causa. Utilizando a classificação quanto à origem das manifestações patológicas definida pelo autor por umidade, trincas e fissuras, patologia de revestimentos.

\subsubsection{Umidade}

A umidade é uma grande vilã para a construção civil, causadora de diversas patologias e que é encontrada na maioria das edificações até mesmo nos dias atuais onde se conhece variadas formas de combatê-la (RESENDE, 2000).

Segundo Lersh (2003), no estado líquido o transporte ocorre por capilaridade, pela força gravitacional ou por gradientes de pressão. Já no estado gasoso, a transferência se dá em decorrência da difusão ou convecção. Os mecanismos que fundamentam a maioria das situações em que ocorre o movimento de água no interior dos materiais porosos são a absorção, a condensação e a capilaridade.

a) Umidade ascendente por capilaridade

A umidade existente no solo migra por entre os poros abertos dos materiais constituintes das estruturas e das paredes de vedações que estejam em contato com ele. Quanto menor o diâmetro dos poros maior será ascensão da água no material (SILVA, 2007).

b) Umidade decorrente de intempéries

Em geral, é ocasionada pela água da chuva e, se combinada com o vento, pode agravar a infiltração com o aumento da pressão de infiltração (RIGHI, 2009; CECHINEL et al., 2021). Segundo Nappi (1995), a energia das 
gotas de água pode provocar penetração direta, sempre que essas gotas caiam em fissuras ou em juntas mal vedadas. Além disso, a ação continuada da chuva pode formar uma cortina de água que, ao escorrer pela parede, pode penetrar nela por gravidade.

\subsubsection{Trincas e fissuras}

As fissuras são aberturas que surgem nos materiais, oriundos, na sua maioria, devido à tração. Quando se observa a existência de fissuras é porque algo não previsto aconteceu, excedendo a capacidade de resistência do material; várias ações podem interferir na estrutura (DEUTSCH, 2013).

Thomaz (1992), destaca as fissuras como sendo as mais importantes patologias devido a três aspectos: o aviso de algum problema sério na estrutura, o comprometimento do desempenho da obra em serviço e o constrangimento psicológico que a fissuração exerce sobre seus usuários.

Segundo a norma NBR 15575 (ABNT, 2013), são classificadas como fissuras as aberturas com menos que 0,6 $\mathrm{mm}$ de espessura e como trincas aquelas com medidas até a $1 \mathrm{~mm}$.

De acordo com Thomaz (1992), as fissuras e trincas podem ser classificadas como:

a) Trincas e fissuras provocadas por deformabilidade excessiva;

b) Trincas e fissuras por recalques diferenciais;

c) Trincas e fissuras provocadas por erros de projeto ou de execução;

d) Trincas e fissuras horizontais.

\subsection{Inspeção}

A definição de inspeção predial de uso e manutenção, de acordo com a norma NBR 15575 (ABNT, 2013), é a verificação das condições de uso e de manutenção preventiva e corretiva da edificação, através de metodologia técnica.

Conforme Tutikian e Pacheco (2013), o estudo de uma patologia deve possibilitar a determinação da origem, do mecanismo e dos danos subsequentes, para que haja avaliação e conclusão sobre as técnicas de recomendações mais eficazes.

a) Inspeção preliminar

Segundo o boletim técnico de Tutikian e Pacheco (2013), a inspeção preliminar consiste na análise de três quesitos: exame visual, antecedentes e análises de ensaios gerais. De posse destas informações é possível determinar a natureza e a origem da patologia.

De acordo com Tutikian e Pacheco (2013), deve ser feita uma avaliação de antecedentes da estrutura e do ambiente. Para a estrutura é importante a obtenção de informações como a idade ou tempo de serviço, natureza e procedência dos materiais constituintes, resistência característica, qualidade e características de construção, idade de início dos problemas, diagnósticos e reparações anteriores, níveis de tensão de trabalho da estrutura, eventuais mudanças de uso, etc.

b) Inspeção detalhada

Posterior à inspeção preliminar, a inspeção detalhada caracteriza-se por ser mais criteriosa na análise de estrutura. Esse rigor depende da natureza da patologia e da experiência do analisador.

A forma de investigação feita durante o diagnóstico deve ser profunda e ordenada. Cada caso deve possuir sua própria metodologia. Para isso, é essencial o conhecimento das técnicas construtivas e das caracteristicas e do comportamento estrutural; dos materiais, da forma de execução e colocação correta e dos factores que podem influir na origem das incompatibilidades, Goicoecha (2006).

\section{Metodologia}

O estudo de caso deste trabalho é composto por um pavimento que possui 1 andar, com $408 \mathrm{~m}^{2}$ de área construída, localizado no município de Congonhas. A edificação localiza-se dentro da área urbana, em ambiente com classe de agressividade II, moderada, de acordo com a NBR 6118 (2014). 
Para a realização deste estudo foi necessária a elaboração de uma base de dados sobre a estrutura já construída, através de entrevista com os responsáveis pela obra, bem como oficiais que trabalharam em sua execução, pois não haviam projetos disponíveis.

Antes de se avaliar as causas das patologias, foi realizada uma pesquisa bibliográfica para se basear na literatura e nas normas o que se apresenta. A Norma de Inspeção Predial Nacional (IBAPE, 2012) fixa as diretrizes, conceitos, terminologia, convenções, notações, critérios e procedimentos relativos à inspeção predial. De acordo com os procedimentos descritos na norma IBAPE (2012), os níveis de inspeção predial podem ser classificados em nível 1, nível 2 e nível 3 (Tabela 1).

Tabela 1 - Classificação dos níveis de inspeção predial segundo a Norma de Inspeção Predial Nacional

\begin{tabular}{|c|c|}
\hline NÍVEIS & CARACTERÍSTICAS \\
\hline $\mathbf{1}$ & $\begin{array}{r}\text { Realizada em edificações com baixa complexidade técnica, de manutenção e de operação de seus } \\
\text { elementos e sistemas construtivos. Normalmente empregada em edificações com planos de manutenção } \\
\text { muito simples ou inexistentes. }\end{array}$ \\
\hline $\mathbf{2}$ & $\begin{array}{r}\text { Realizada em edificações com média complexidade técnica, de manutenção e de operação de seus } \\
\text { elementos e sistemas construtivos, de padrões construtivos médios e com sistemas convencionais }\end{array}$ \\
\hline $\mathbf{3}$ & $\begin{array}{r}\text { Realizada em edificações com alta complexidade técnica, de manutenção e operação de seus elementos e } \\
\text { sistemas construtivos, de padrões construtivos superiores e com sistemas mais sofisticados. }\end{array}$ \\
\hline
\end{tabular}

Após a determinação do nível de inspeção predial, foi identificado visualmente o processo patológico em questão. A seguir, o mesmo foi fotografado e, então, sua abertura foi medida, parede a parede, utilizandose um escalímetro padrão. As fendas são classificadas conforme sua espessura como: fissuras, trincas ou rachaduras. Essas fendas são manifestações patológicas que afetam a construção civil e que podem interferir negativamente na estética, na durabilidade e, principalmente, nas características estruturais da obra. Neste estudo a classificação das fendas foi realizada de acordo com Oliveira (2012) conforme os dados apresentados na Tabela 2, a partir das medições realizadas.

Tabela 2 - Classificação das fendas de acordo com a espessura de abertura

\begin{tabular}{|c|c|c|}
\hline TIPO DE FENDA & CARACTERÍSTICAS & REFERÊNCIA \\
\hline FISSURA & Aberturas com até $0,5 \mathrm{~mm}$ de espessura de espessura de parede a & Oliveira (2012) \\
parede. & $\begin{array}{c}\text { Aberturas entre } 0,5 \mathrm{~mm} \text { até } 1,5 \mathrm{~mm} \text { de espessura de parede a parede. } \\
\text { TRINCA }\end{array}$ & Oliveira (2012) \\
\hline RACHADURA & Aberturas entre $1,5 \mathrm{~mm}$ até $5 \mathrm{~mm}$ de espessura de espessura de & Oliveira (2012) \\
\hline
\end{tabular}

Após o registro da abertura de cada trinca, fissura e rachadura essas fendas foram pintadas nas suas extremidades para garantir que se houvesse aumento em amplitude este fosse visualmente registrado. Por fim, com os dados obtidos em campo, realizou-se a classificação das patologias quanto à origem, quanto ao risco inerente à resistência da estrutura e à sua evolução. Para a determinação quanto à origem do processo patológico verificou-se a conformação da patologia em estudo, bem como seus possíveis fatores formadores na literatura. Em relação à resistência da estrutura as patologias foram classificadas, de acordo com IBAPE (2012), em:

a) Risco mínimo: risco de causar pequenos prejuízos à estética ou atividade programável e planejada, sem incidência ou sem a probabilidade de ocorrência dos riscos críticos e regulares, além de baixo ou nenhum comprometimento do valor imobiliário.

b) Risco médio: risco de provocar a perda parcial de desempenho e funcionalidade da edificação sem prejuízo à operação direta de sistemas, e deterioração precoce. 
c) Risco crítico: risco de provocar danos contra a saúde e segurança das pessoas e do meio ambiente; perda excessiva de desempenho e funcionalidade causando possíveis paralisações; aumento excessivo de custo de manutenção e recuperação; comprometimento sensível de vida útil.

A estrutura em estudo foi acrescida de um pavimento superior, o que causa uma maior imposição de tensão sobre o solo. Portanto, durante os oito meses seguintes estes processos patológicos foram acompanhados e classificados como inertes ou ativos.

Na Figura 1 detalha-se a sequência realizada para diagnóstico das manifestações patológicas na edificação, utilizada neste estudo.

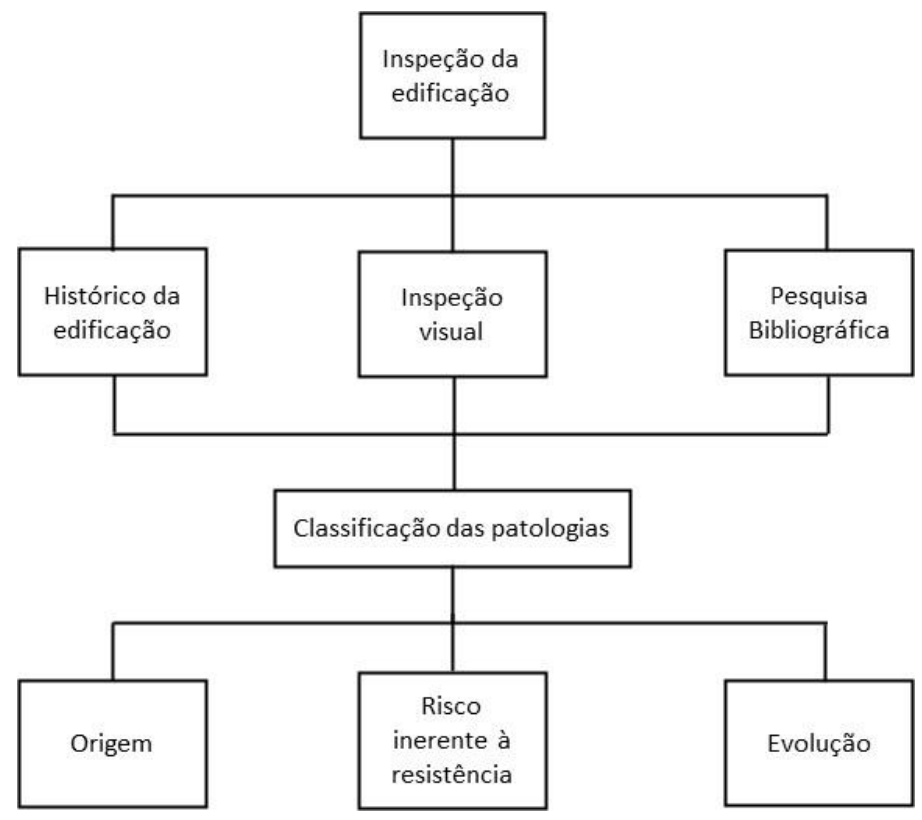

Figura 1 - Metodologia simplificada utilizada neste estudo

\section{Resultados e discussão}

A inspeção visual foi realizada para verificação dos processos patológicos presentes neste estudo. A partir da inspeção visual foram utilizadas as normativas vigentes para identificar as causas das patologias observadas e classificá-las de acordo com seu grau de periculosidade para a estrutura.

A inspeção realizada foi de nível 1 da norma do IBAPE (2012), devido à baixa complexidade da estrutura, uma edificação de um pavimento prestes a receber uma ampliação de um pavimento superior. Obtidos os dados das patologias, foram fotografadas e seus limites foram pintados, para que se houvesse aumento de amplitude pudesse ter sido verificado. Neste trabalho não foram realizados ensaios sobre as patologias, apenas as suas devidas classificações de acordo com a norma supracitada. Para facilitar o entendimento das posições onde foram encontrados os problemas patologias, foi elaborado um mapa de danos, conforme apresentado na Figura 2.

A Figura 3 apresenta fissuras com espessuras inferiores a dois milímetros de abertura, associadas a causas comuns a estruturas na região: o recalque diferencial e a ausência de juntas de dilatação na laje. A manifestação de fissuras na superfície da laje e na alvenaria de vedação são causadas por um esforço de tração. Logo, o processo patológico foi formado pela falta de juntas de dilatação térmica na laje da estrutura, associada ao recalque do terreno. Como não notou-se alargamento na fissura durante a construção do pavimento superior ao estudado, conclui-se que a fissura está inerte, e portanto não existe risco para a ocupação. 


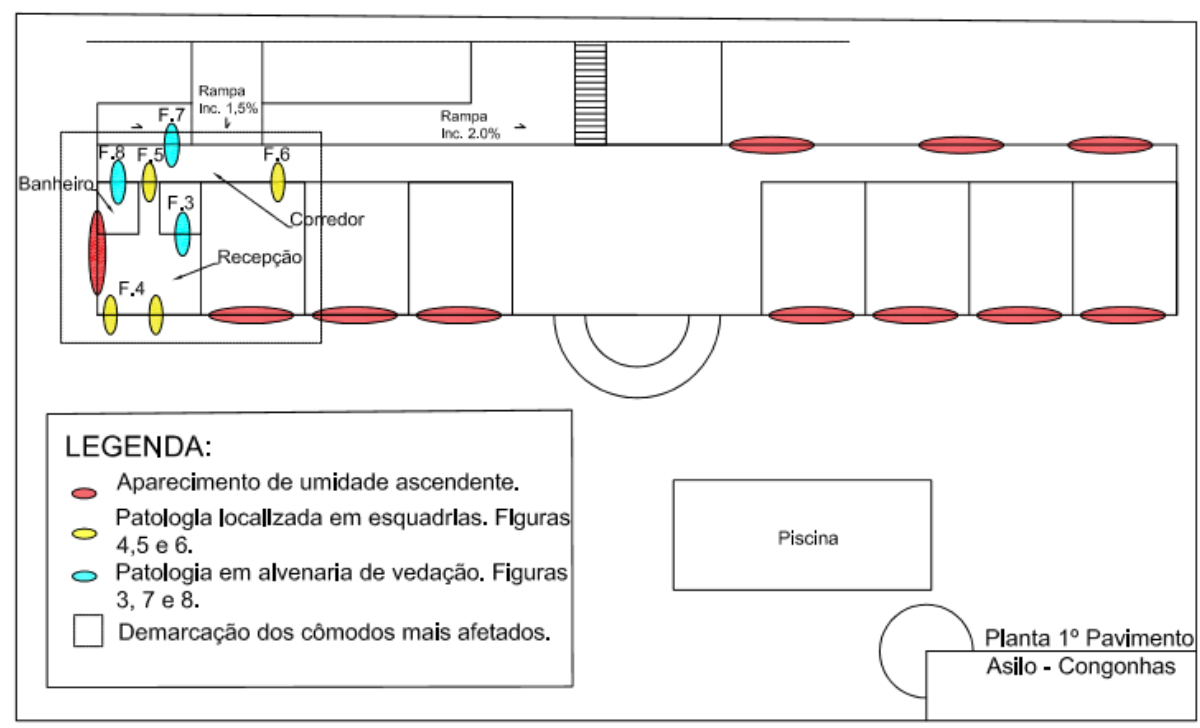

Figura 2- Mapa de danos da edificação $1^{\circ}$ Pavimento

Na Figura 4, são apresentadas patologias em torno da esquadria. Verificou-se que a janela possui verga e contraverga que funcionam como travamento para janela. Foram verificadas as manifestações patológicas, observou-se dois fatores morfológicos distintos, inicialmente a má execução de vergas e contravergas, que existem na edificação, e também a umidade ascendente. Observou-se que umidade enfraquece a argamassa deixando-a pulverulenta, que já solicitada a esforços não consegue resistir e apresenta as primeiras trincas. A má execução dos elementos estruturais, vergas e contra verbas, contribuiu para o surgimento de fissuras. Devido ao tempo que a edificação foi ampliada não se observou aumento, nem o seu alargamento e logo pode-se classificar o grau de risco da patologia em questão como baixo

A Figura 5 apresenta uma trinca formada na parte superior da porta do ambiente estudado. De acordo com a inspeção realizada em campo na qual foi realizado a medição da espessura da trinca, que apresentou uma largura de três milímetros. Destaca-se que ao longo do tempo não se observou evolução com o decorrer da construção do pavimento superior. Portanto, como não houve aumento em espessura ou ampliação, o risco avaliado é baixo, porém, o prejuízo estético é elevado e causa insegurança ao ocupante da edificação.

A fissura mostrada na Figura 6 ocorre na parte externa do banheiro do ambiente recepção. Porém, verifica- se que a patologia é distinta da relatada anteriormente, pois a conformação e angulação das fissuras é diferente. Enfim, pode-se associar as causas das fissuras, devido a sua conformação particular, ao recalque diferencial da parte frontal do prédio associado a má execução da alvenaria de vedação e a ausência, neste caso de verga e contraverga na janela. A trinca e as fissuras não evoluíram com a construção do segundo pavimento, portanto são avaliadas com o grau de risco baixo.

Na Figura 7 é apresentada uma trinca vertical e profunda no parapeito. A trinca na vertical indica que houve erro construtivo e que não foi realizada a viga de amarração à meia altura. Logo, observa-se que este fator está associado a umidade ascendente presente, que causa a eflorescência na parte inferior da alvenaria e enfraquece muito a argamassa, o que faz com que sem resistência se desprenda (Figura 6). Portanto, o risco avaliado como grau baixo, mesmo tendo um aspecto visual ruim, não apresenta ameaça de instabilidade à estrutura ou a segurança dos ocupantes.

No corredor do edifício estudado encontra-se uma fissura na janela do banheiro do primeiro leito, conforme mostrado na Figura 8. A fissura acima está localizada na entrada do corredor do prédio e de acordo com a avaliação da inspeção visual pode estar associada ao recalque diferencial. Verificou-se que o prédio apresenta enormes problema de umidade e por consequência a argamassa enfraquecida, o que pode ter contribuído significativamente para agravar o recalque na estrutura. Durante o acompanhamento da obra, após a construção do segundo pavimento, várias inspeções foram realizadas e a trinca não evoluiu, se mostrando estável. Portanto, foi avaliada como grau de risco baixo. 
Por fim, todas as manifestações patologias identificadas neste estudo possuem o grau de risco avaliado em baixo, de acordo com a normatização do IBAPE (2012).

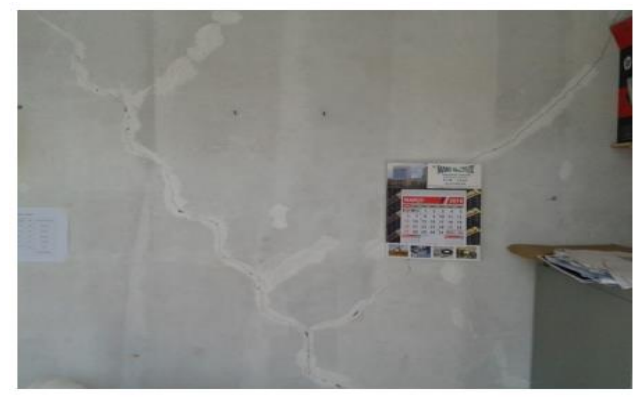

Figura 3 - Fissuras na alvenaria da recepção

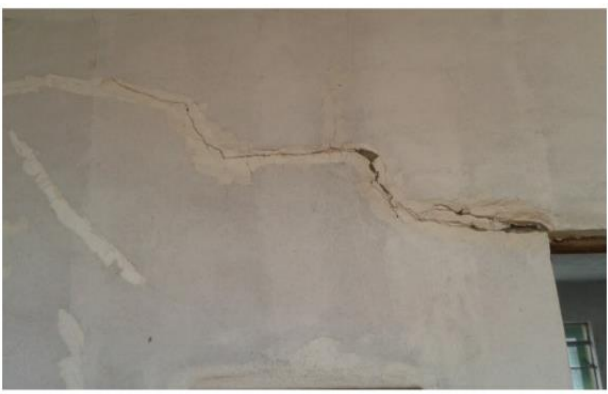

Figura 5 - Trinca sobre porta

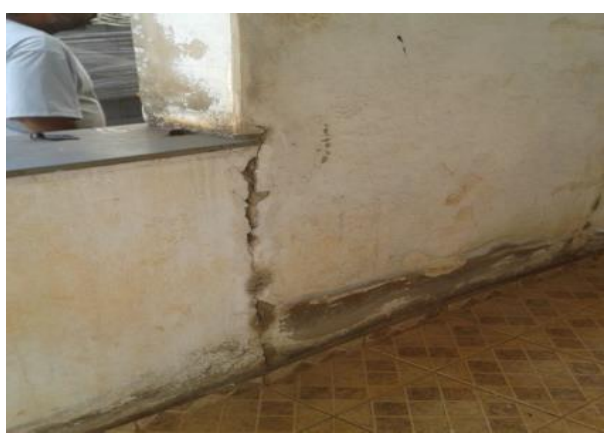

Figura 7 - Trinca vertical parapeito

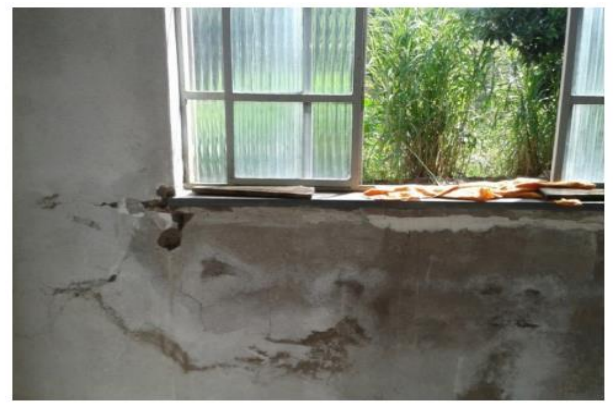

Figura 4 - Janela do ambiente recepção

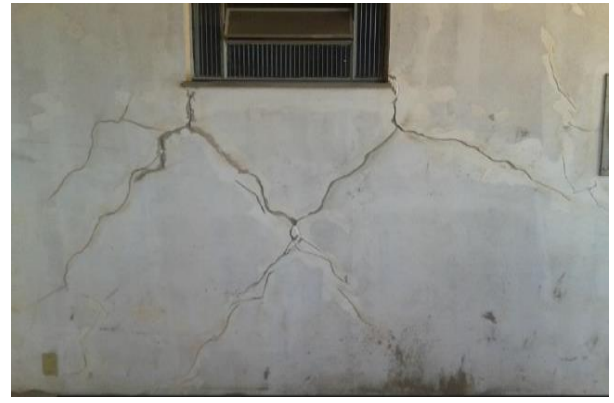

Figura 6 - Trincas em janela de banheiro

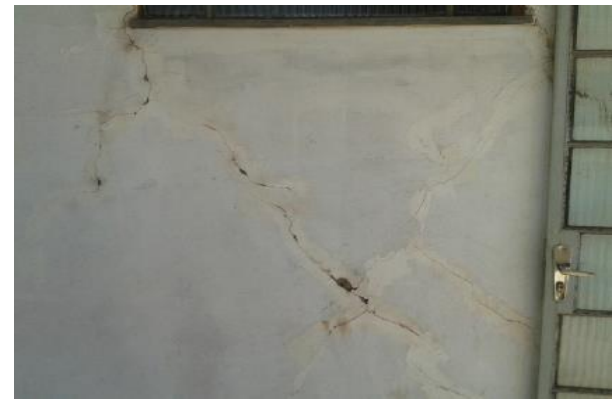

Figura 8 - Trincas em janela de banheiro

\section{Conclusões}

Este trabalho dedicou-se a analisar as patologias mais frequentes em alvenaria de vedação. Aponta-se a grande importância de que as entidades gestoras e moradores dos edifícios que contém alvenarias com patologias, reservem verbas nos seus orçamentos, para garantir a melhoria no conforto do usuário e ocupação do edifício. Visto que, as alvenarias apresentam sintomas que podem estar ligados a problemas estruturais sérios e que podem levar uma edificação à ruína.

Para a elaboração desta pesquisa foi realizado o levantamento das principais patologias, bem como suas origens e formas, sendo que a deterioração do concreto e o recalque são vistos como mais preocupantes. As patologias presentes foram verificadas e permaneceram inertes após a construção do pavimento superior.

Quanto as manifestações patológicas como as trincas, fissuras e rachaduras foram abertas mecanicamente e tratadas com argamassa expansiva e a seguir foi feito o acabamento para que não permanecesse o dano estético à estrutura, o que causava preocupação aos usuários quanto à sua segurança. Desta forma, expõese a preocupação em reduzir as causas dessas patologias, melhorando a qualidade de projetos, emprego de materiais certificados e adoção de mão de obra qualificada. 
De acordo com a análise dos dados, ressalta-se a necessidade corrente do projetista pensar não somente na economia de materiais na execução de uma obra, mas também na maneira como pode vir a afetar a durabilidade das estruturas e componentes. Desta forma, percebe-se o quanto é viável que sejam pensadas medidas profiláticas para se evitar o surgimento das patologias. Em suma, a grande maioria dos problemas patológicos encontrados podem ser tratados e superados com técnicas simples de recuperação. Destaca-se que o processo de manutenção não se deve encerrar na execução dos serviços prescritos, mas com o registro detalhado do caso.

Sendo assim, mantém-se formalizado o histórico da obra para possíveis intervenções futuras. Junto aos processos de manutenção, é de extrema importância a execução de procedimentos de vistoria dos elementos construtivos.

\section{Referências Bibliográficas}

ASSOCIAÇÃO BRASILEIRA DE NORMAS TÉCNICAS (2013). NBR 15575: Edificações Habitacionais Desempenho. Rio de Janeiro-RJ.

ASSOCIAÇÃO BRASILEIRA DE NORMAS TÉCNICAS(2014). NBR 6118: Projeto de estruturas de concreto Procedimento. Rio de Janeiro-RJ.

DEUTSCH, S. F. (2013). Perícias de engenharia: a apuração dos fatos. 2.Ed.São Paulo: Leud, 91-97 p.

FIGUEIREDO, A. C. (2003). Proposta de Metodologia para estudo de patologias nas edificações do CTA - São José dos Campos. Monografia (Graduação). São José dos Campos - SP, 53-56 p.

GOICOECHA, Mạ., MONJíN, V. (2006). Intervención en Patología de la Eficación. Actuaciones en un Diagnóstico. Informes. 2o Encontro sobre Patologia e Reabilitação de Edifícios. PATORREB2006. - Porto, FEUP.

INSTITUTO BRASILEIRO DE AVALIAÇÕES E PERÍCIAS DE ENGENHARIA -IBAPE (2012). Norma de inspeção predial nacional. São Paulo.

LERSCH, I. M. (2003). Contribuição para identificação dos principais fatores e mecanismos de degradação em edificações do patrimônio cultural de Porto Alegre. Dissertação (Mestrado em Engenharia Civil) Universidade Federal do Rio Grande do Sul. Porto Alegre -RS.

NAPPI, S. C. B. (1995). Umidade em paredes. In: "Congresso Técnico-Científico de Engenharia Civil". Anais. Universidade Federal de Santa Catarina. Florianópolis-SC.

OLIVEIRA, A. M. (2012). Fissuras e rachaduras causadas por recalque diferencial de fundações. 2012. $96 f$. Monografia (Espacialização em Gestão em Avaliações e Perícias) - Universidade Federal de Minas Gerais, Minas Gerais.

POSSAN, E.; DEMOLINER, C. A. (2013). Desempenho, durabilidade e vida útil das edificações: Abordagem geral. Revista técnico científica do CREA-PR, (1), 1-14.

RESENDE, Z. S. (2000). Processos preventivos e corretivos no tratamento da umidade em construções. Dissertação (Mestrado). Campinas-SP.

RIGHI, G. V. (2009). Estudo dos Sistemas de Impermeabilização: Patologias, Prevenções e Correções - Análise de casos. Dissertação (Mestrado em Engenharia Civil) - Universidade Federal de Santa Maria. Santa Maria - RS.

SILVA, A. F. (2007). Manifestações patológicas em fachadas com revestimentos argamassados, estudo de caso em edifícios de Florianópolis. Dissertação (Mestrado). Florianópolis-SC, 45 p.

SOUZA, V. C. \& RIPPER, T. (1998). Patologia, recuperação e reforço de estruturas de concreto. Editora Pini, São Paulo-SP.

THOMAZ, E. (1992). Trincas em edifícios: causas, prevenção e recuperação. Ed. PINI ,São Paulo-SP.

TUTIKIAN, B.; PACHECO, M. (2013). O que é Inspeção, Diagnóstico e Prognóstico na Construção Civil. Boletim Técnico no 01, Mérida, México: Alconpat Internacional, 6-11 p. 